\title{
Mikroplastikoen inpaktua, hedapena eta mikroorganismoen bidezko biodegradazioa ozeanoetan
}

\author{
(Impact, expansion and biodegradation by microorganisms of \\ microplastics in the ocean)
}

Zuriñe Baña*

Mikroorganismo itsastarrak ikerketa taldea. Immunologia, Mikrobiologia eta Parasitologia saila, Zientzia eta Teknologia Fakultatea. Euskal Herriko Unibertsitatea (UPV/EHU)

\begin{abstract}
LABURPENA: Mikroplastiko sintetikoak $(\leq 5 \mathrm{~mm})$ gero eta kantitate handiagoan aurkitzen diren ingurumen-kutsatzaileak dira, mundu osoko estuarioetan eta itsas sistemetan metatzen direnak ezin direlako era errazean degradatu. Mikroplastikoen ugaritasunak, tamaina txikiak eta dentsitate baxuak korronte ozeanikoen bidez sakabanatzen eta garraiatzen laguntzen diete. Kutsatzaile horiek erabilera handiko produktuen isurketaren bidez hel daitezke ur-sistemetara, edota ingurumen-baldintza aldakorren pean (izozte-desizoztea, erradiazio ultramorea, ur-korronteak, eta abar) deskonposatzen diren hondar plastiko handiagoetatik sor daitezke itsasoan bertan. Plastiko horien mundumailako urteroko fabrikazioa asko handitu da azken hamarkadan, eta konponbide bat laster ez bada eskaintzen, itsasoko mikroplastikoen metaketak eta hedapenak handiagotzen jarraituko du, horrek dakartzan ondorio ekologikoekin eta toxikologikoekin. Alde batetik, mikroplastikoak mikroorganismoen kolonizaziorako aproposak diren gainazalak dira, komunitate naturalen aktibitatean eta konposizioan aldaketak sustatzen dituztenak, eta, ondorioz, ziklo biogeokimikoetan aldaketak ere eragiten dituztenak. Beste alde batetik, mikroplastikoak eta adsorbituta daramaten kutsatzaile kimikoak zein metal astunak ingeritzeko potentzial altua dute itsas animaliek, haien ehunetan eta organoetan metatzen baitira, eta harrezkero, sare trofikoetan zehar transferitu eta biohanditu. Gainera, mikroplastikoek patogenoen, biotoxinen eta antibiotikoekiko erresistenteak diren geneen sakabanaketan parte hartzen dute, eta osasun publikoan eragin zuzena izan dezakete. Naturan badaude entzimen bidez mikroplastikoak guztiz edo partzialki degradatzeko eta energia-iturri moduan erabiltzeko gai diren mikroorganismoak. Beraz, mikroplastikoak degrada ditzaketen mikroorganismoak identifikatzea etorkizun handiko estrategia da biodegradazio naturala errazteko eta ekosistema naturalen garbiketan laguntzeko, ingurumenaren aurkako inpakturik eragin gabe.
\end{abstract}

HITZ GAKOAK: mikroplastikoa, ozeanoa, mikroorganismoak, bioerremediazioa, biodegradazioa.

ABSTRACT: Synthetic microplastics $(\leq 5 \mathrm{~mm})$ are environmental pollutants found in ever-increasing quantities, accumulating in estuaries and marine systems worldwide, because they cannot be easily degraded. Their abundance, small size, and low density help in their dispersal and transport by ocean currents. These contaminants can reach aquatic systems by pouring widely used products or can be produced from larger plastic debris that is decomposed due to exposure to environmental conditions (freeze thaw, ultraviolet radiation, water currents, etc.). Worldwide annual manufacturing of these plastics has increased greatly over the past decade, and if a solution is not offered soon, the accumulation and expansion of marine microplastics will continue to increase, with the ecological and toxicological effects that it entails. On the one hand, microplastic surface is suitable for colonization of microorganisms that provoke changes in the activity and composition of natural communities, causing changes in biogeochemical cycles. On the other hand, marine animals have a high potential for ingestion of microplastics and chemical contaminants or heavy metals that are adsorbed, which accumulate in their tissues and organs, and that are captured, transferred and bioincremented through trophic networks. In addition, microplastics participate in the dispersion of pathogens, biotoxins and antibiotic resistant genes, and can have a direct effect on public health. In nature, there are microorganisms capable of degrading all or part of the microplastics by enzymes and using them as an energy source. Therefore, identifying microorganisms that can degrade microplastics is a promising strategy to facilitate natural biodegradation and assist in the cleaning of natural ecosystems without causing adverse environmental impacts.

KEYWORDS: microplastic, ocean, microorganism, bioremediation, degradation.

* Harremanetan jartzeko / Corresponding author: Zuriñe Baña, Mikroorganismo itsastarrak ikerketa taldea. Immunologia, Mikrobiologia eta Parasitologia saila, Zientzia eta Teknologia Fakultatea. Euskal Herriko Unibertsitatea (UPV/EHU), Sarriena auzoa, zg, 48940 Leioa, Bizkaia. Euskal Herria. - zurine.bana@ehu.eus - https://orcid.org/0000-0002-4210-2537.

Nola aipatu / How to cite: Baña, Zuriñe (2020). «Mikroplastikoen inpaktua, hedapena eta mikroorganismoen bidezko biodegradazioa ozeanoetan»; Ekaia, ale berezia 2020, 253-274. (https://doi.org/10.1387/ekaia.21081).

Jasoa: 09 iraila, 2019; Onartua: 12 abendua, 2019

ISSN 0214-9001 - elSSN 2444-3255 / (c) 2020 UPV/EHU

(c) (i) () Obra hau Creative Commons Atribución 4.0 Internacional-en

lizentziapean dago 


\section{SARRERA}

Egunero hondar plastikoen masa handi bat isurtzen da ingurumenera, eta haietako askoren azkeneko norakoa ozeanoa da. 2006. eta 2016. urteen artean hondar plastikoen birziklatzea \%79an emendatu zen arren [1], estimatzen da urtero 4,8 eta 12,7 milioi tona bitarte plastikok amaitzen duela ozeanoetan [2]. Eriksen-ek eta haren lankideek berri eman zuten 2014an [3] munduko ozeanoetan 270.000 tonako pisua izan dezaketen 5,25 bilioi partikula plastiko flotatzen egon daitezkeela. Zifra horiek kezkagarriak izanagatik ere, plastikoaren mundu-mailako eskariak gora egiten jarraitzen du: 2016an, adibidez, planetan 348 milioi tona metriko polimero plastiko inguru produzitzera heldu gara [1]. Ekoizpenaren joera hori, plastikoen erabilera-patroiak eta demografiaren gorako joera ikusita, ozeanoetan hondar plastikoen eragina hurrengo urteetan areagotu egingo dela pentsa daiteke. Izan ere, hura galarazteko zeozer egiten ez bada, aurreikusi dute 2050erako 12.000 milioi tona metriko hondakin plastiko isuriko direla ingurumenean [4]. World Economic Forum-aren arabera, 2050. urterako, munduko ozeanoetan arrain baino plastiko gehiago egongo da.

Plastiko handiek itsasoko animaliengan dituzten kalteen ikusgarritasunak alarma soziala sortu du azken hamarkadan. Baina arreta gutxiago jarri zaio $5 \mathrm{~mm}$ baino txikiagoak diren partikula plastikoei, mikroplastikoei hain zuzen ere [5]. Hondar-plastiko handiak itsasora heltzen direnean aldaketak gertatzen hasten dira, eta, denborarekin, partikula txikiagoetan zatikatzen dira, eta mikroplastiko bihurtzen dira. Horiek plastiko handiak baino kopuru handiagoan aurkitu daitezke itsaso zabalean, eta ezin dira itsasotik eskuz ezabatu, daukaten tamaina txikia eta ikusgarritasun eskasa dela eta. Gainera, ez dira erraz degradatzen, eta ingurumenean metatzen dira. Mikroplastikoen metaketak mehatxu bai fisikoa eta bai kimikoa dakarkio itsasoetako eta ozeanoetako segurtasun ekologikoari. Izan ere, nonahi aurki daitezke [6]; toxikoak izan daitezkeen kutsatzaile organikoak eta bestelako gehigarri kimikoak garraiatzeko ahalmena dute [7]; baita patogenoak, biotoxinak eta antibiotikoekiko erresistentziarako geneak sakabanatzeko ere [8,9]; mikroplastikoek itsas biotan barneratzeko ahalmen altua daukate, hesteetan metatzen baitira eta zirkulazio-aparatuaren funtzionamenduan eragiten baitute [5, 10]; itsasoko sare trofikoan metatzeko gaitasuna dute [11]; eta mikroorganismoen komunitatearen konposizioan eta funtzioan eragin dezakete, karbonoaren zikloan aldaketak bultzaraziz eskala globalean [12, 13].

Arazo global honen aurrean, mikroplastikoen metaketa geldiarazteko beharra dago. Horretarako, gizartearen kontsumo-ohituran aldaketak bermatu, plastikoaren erabilera masiboa txikiagotu, plastikoen birziklapena sustatu edota ordezko materialen ikerketa bultzatu beharko litzateke. Bestetik, hainbat urteren buruan ozeanoetan metatutako mikroplastikoen garbitzeak berebiziko premia du. Hala ere, ez dago ur-sistemetako mikroplas- 
tikoak guztiz ezabatzeko modu eraginkorrik. Gaur egun, ekosistema honen biziraupenerako, funtsezkoa da mikroplastikoen biodegradaziorako metodo egokiak garatzea. Horretarako, ezinbestekoa da ulertzea mikroplastikoen iturriak, mugimendua, konposizioa, degradazioa eta itsas biotarekin edota materia organikoarekin dituen interakzioak.

Berrikusketa honetan, literaturan aurki daitekeen mikroplastikoen iturriei, konposizioari eta banaketari buruzko informazioa biltzen da, bai eta kutsatzaile hauen presentziak ozeanoetan izan ditzakeen inpaktu biologikoari eta ondorio ekologikoei buruzko informazioa ere. Honetaz gain, polimero horien degradazio-prozesua aztertzen da, mikroorganismoek izan dezaketen eginkizunean zentratuz.

\section{MIKROPLASTIKOEN ITURRIAK ETA MOTAK}

Mikroplastikoak ozeanoetan zabor artifizialen atalean metatu izan dira gutxienez azken lau hamarkadetan [15]. Itsasora bide desberdinetatik hel daitezke, baina badirudi ozeanoetako plastikoaren kutsaduraren \%80 lurreko jardueren ondorioz heltzen dela [16]. Zaintza pertsonaleko produktuetan, margoetan edota arropa sintetikoan egon ohi diren mikroplastikoko perlak industrietako zein etxeetako drainatze-sistemen bidez irits daitezke ur-ingurumenera [17]. Era berean, hondakin-uren tratamendurako araztegiak itsasoko mikroplastikoen iturri garrantzitsuak izan daitezke, bai efluenteen bai hondar-lohien bidez [18]. Mikroplastikoak ibaien edo isurketaren bidez [19, 20], haizearen edo ekaitzen bidez [21] edota ur-korrontearen bidez irits daitezke erraz itsasora. Gainera, hondakindegietako makroplastikoen degradaziotik eratorritako plastiko puskek, arrantzaleek galdutako arrantza-erremintek [22] edo itsasontzi-garbiketarako erabiltzen diren urratzaile industrialek ere, itsasoko hondar plastikoen kantitatea emendatzen dute [17, 23].

Mikroplastikoak mota desberdinekoak izan daitezke, jatorriaren edo konposizioaren arabera. Jatorriaren arabera, bi taldetan sailkatzen dira. Alde batetik, lehen mailako mikroplastikoak dauzkagu, industriako zein etxeko produktuetarako ekoizten diren tamaina mikroskopikoko plastikoak direnak [23]. Mikroplastiko horiek eguneroko bizitzan erabiltzen diren produktuen ekoizpenean erabiltzen dira [22-24]; besteak beste, honako hauetan: aurpegia garbitzeko produktuetan, hortzak garbitzeko pastetan, bainurako geletan, usain-kengarrietan, makillaje-produktuetan, bizarra mozteko kremetan, ile-tindatzaileetan, azazkal-esmalteetan, intsektu-uxagarrietan, eguzkitik babesteko kremetan, arropa sintetikoetan eta garbiketa-produktuetan. Arrunki, produktu horietako hondakinek isurbideen bitartez hel daitezke ingurumenera [24]. Beste alde batetik, itsasora iristen diren tamaina handiko hondar plastikoek prozesu fisikoak, kimikoak eta biologikoak ja- 
saten dituzte, eta, denborarekin, partikula txikiagoetan zatikatzen eta bigarren-mailako mikroplastikoak sortzen dira [22, 23, 25]. Bai lehen mailako mikroplastikoak, bai bigarren mailakoak, kontzentrazio altuetan agertzen dira itsas ekosistemetan [26].

Ozeanoetan aurki daitezkeen mikroplastiko gehienak, bizitza baliagarri nahiko motza duten paketatze-produktuetatik eratorriak dira. Polietilenoaren kasua da: bai dentsitate baxuko polietilenoa, normalean plastikozko poltsak, sareak, aro-plastikoak, lastotxoak eta botilak ekoizteko erabiltzen dena; bai dentsitate altuko polietilenoa, esne- eta zuku-briketan aurkitu daitekeena ere. Ugariak dira, halaber, polipropileno plastikoak, soken eta plastikozko tapoien ekoizpenean erabiltzen direnak, eta poliestirenoak, plastiko-tresnen, janari-edukiontzien eta apar-erretiluen ekoizpenean erabiltzen direnak. Polibinilo kloruroa, plastikozko mintzak eta edalontziak ekoizteko erabiltzeaz gain, bizitza baliagarri askoz luzeagoa duten eraikuntza-materialetarako ere erabiltzen da $[14,27]$.

\section{MIKROPLASTIKOEN BANAKETA OZEANO GLOBALEAN}

Ozeanoetan egindako mikroplastikoen gaineko ikerketek haien nonahikotasuna frogatu dute. Partikula plastiko txiki horiek oso ugariak dira, eta ozeano guztietan hedatuta daude [6, 28-30]. Haien ugaritasunak, tamaina txikiak $(<5 \mathrm{~mm})$ eta dentsitate baxuak lagundu egiten dute korronte ozeanikoen bidez sakabanatzen eta garraioan [30, 31]. Mikroplastikoak oso leku desberdinetan aurkitu dira: ur sakonetan [32], sakontasun gutxiko kostaldeko uretan [33], hondartzetan [34], sedimentuetan [35] edota Artikoko izotzean $[36,37]$.

Gaur egun, mikroplastikoak munduko ozeano guztietatik zabalduta daudela onartzen da. Bira ozeanikoak eta ertz konbergenteak metaketarako eskualde bereziki erakargarriak dira, korronteen errotazio-patroiek mikroplastikoen kontzentrazio altuak harrapatuta gelditzen laguntzen dutelako [38]. Izan ere, Ipar Pazifikoko Bira «plastikozko kontinentea» izenez ezagutzen da [39]. Eskualde horretan, azken berrogei urteetan mikroplastikoen kontzentrazioa bi ordenatan emendatu da, 0,003 partikula $\mathrm{m}^{-3}$-tik 0,425 partikula $\mathrm{m}^{-3}$-ra [40]. Tamalez, hau ez da zabortegi bihurtu den eskualde ozeaniko bakarra. Hego Pazifikoko Biran eta Ipar Atlantikoko Biran ere mikroplastikoen kontzentrazioa handituz doala ikusi da, non gaur egun 0,0054 partikula $\mathrm{m}^{-3}$ eta 0,0041 partikula $\mathrm{m}^{-3}$ detektatu baitira, hurrenez hurren [41, 42]. Ipar-Mendebaldeko Mediterraneo Itsasoko gainazal uretan behatutako mikroplastikoen kontzentrazioak $\left(0,27\right.$ partikula $\left.\mathrm{m}^{-3}\right)$ ere kezkagarriak dira [43]. Alor honetan Ozeano Indikoa asko aztertu ez bada ere, han ere mikroplastikoen presentzia antzeman da $\left(0,4\right.$ partikula $\left.\mathrm{m}^{-3}\right)$ [44]. Ozeanoetako korronte konbergenteak direla eta, Artikoko Barents Itsasoa- 
ren eremuan ere, plastikoz betetako bira bat eratu da [45]: horrek adierazten du ez dela plastikorik gabeko ozeanorik gelditzen.

Munduko ozeanoen gainazaletan barreiatuta, 268.940 tona plastiko $(5,25$ bilioi partikula) egon daitekeela uste da [3] (1. irudia). Baina ozeanoen gainazalean detektatzen diren mikroplastikoen kantitateak eta urtero ematen diren isurketa-balioak (ehun aldiz handiagoak) ez datoz bat [3], eta horrek bahiketa-mekanismoren bat dagoela iradokitzen du. Mikroplastikoen dentsitateak ur-zutabean duten banaketan eragina dauka; hortaz, itsasoko ura baino dentsitate baxuagoa dutenak gainazalean flotatzen geldituko dira [46], eta dentsitate handiagokoak, berriz, hondoratu egiten dira [35]. Gainera, mikroorganismoen eta materia organikoaren atxikipenaren bidezko agregatuen eraketak mikroplastiko horien hondoratzea erraztuko luke, eta sedimentuetan mikroplastikoen metaketa sustatu [22, 47]. Itsas sedimentuetan metatutako mikroplastikoen kantitatearen ondorioz, geruza fosil iraunkor bat eratu da, Antropozenoaren seinale estratigrafikoa bihurtu dena [48].
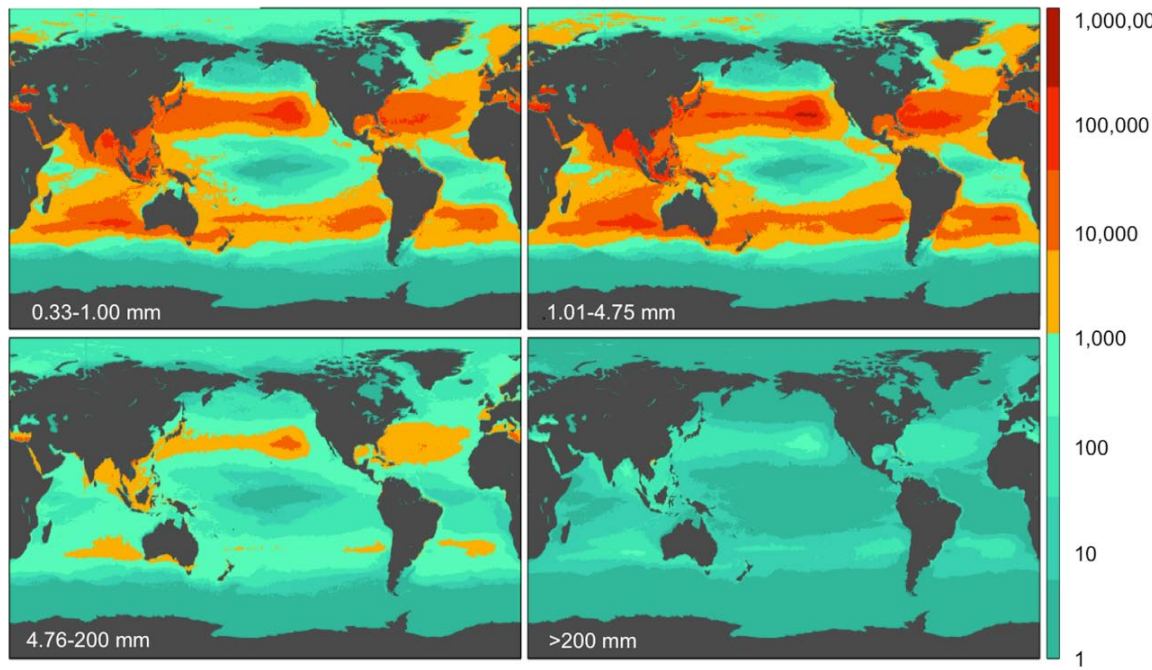

1. irudia. Ozeanoaren gainazalean egon daitezkeen mikroplastiko-dentsitatearen aurreikuspena (partikula $\mathrm{km}^{-2}$; ikusi kolore-barra), plastikoen tamainaren arabera (0,33-1,00 mm, 1,01-1,75 mm, 4,76-200 mm eta > $200 \mathrm{~mm})$. Irudia Eriksen et al. (2014) artikulutik aterea da [3].

Oro har, mikroplastikoen kantitatea kostaldeko ekosistemetan itsaso zabalean baino handiagoa izan ohi da, batez ere azaleratzeetan [49] edota hiri edo ibai-bokalen batetik hurbil dauden eskualdeetan [50]. Lekuko klimabaldintzek eragin handia dute kostaldeko uretan mikroplastikoen agerpe- 
nean. Adibidez, ekaitz baten ostean, mikroplastikoen kantitatea handituko duten sedimentuen azaleratzea [51] eta isurketen areagotzea gertatzen dira. Kostaldeko itsas uretan ager daitezkeen kutsadura-iturri puntualak ezagutzea, ibai-uren sarrera eta hondakin-uren drainatzea barne, erabilgarria izan daiteke ekosistema horietan mikroplastikoen kantitatea kontrolatzeko eta haien inpaktua ulertzeko.

\section{MIKROPLASTIKOEN INPAKTUA SARE TROFIKOAN}

Plastikozko objektu handiak mikroplastikoetan deskonposatzen diren heinean, haien ugaritasuna itsas ingurumenean handituz doa. Era horretan, mikroplastikoak itsasoko organismoentzat eskuragarriago egongo dira, eta ekosisteman izan dezaketen inpaktu potentziala handituko da. Mikroplastikoen irensketa munduko eskualde ozeaniko guztietan maila trofiko desberdineko itsas organismoetan gertatzen dela detektatu da: zooplanktonean eta kopepodoetan [10], zeintzuen bidez goiko maila trofikoetara ere iritsiko diren; ornogabeetan, bereziki muskuiluak edo lanpernetan, animalia iragazleak [52, 53]; arrainetan [54] eta haiek jaten dituzten hegaztietan [55], dortoketan [56] eta ugaztunetan [57]. Gizakiok ere inkontzienteki mikroplastikoak irensten ditugu egunero, adibidez itsas gatz komertzialaren bitartez edo beste hainbat elikagairen bitartez [58]. Itsasoko organismoei dagokienez, irensketa askotan ustekabekoa da, zeren eskuarki elikatu ohi diren flagelatuen edo diatomeoen tamainaren antzekoa baitute (200 nm-2 $\mu \mathrm{m})$ [14]. Tamainak ez ezik, plastiko-partikula txiki horien koloreak, dentsitateak, formak, kargak, multzokatzeak eta ugaritasunak ere eragiten diote itsasoko organismoentzako eskuragarritasun potentzialari [59]. Horrela, mikroplastikoen ezaugarrien arabera, organismo batzuek espezifikoki eraso diezaiekete haien janariarekin nahasiz [60].

Bestalde, kutsatzaile kimikoak mikroplastikoen gainazal hidrofobikora adsorbatzen dira, bai itsas uretan egon daitezkeenak edota plastikoen ekoizpen-prozesuan biguntzaile edo estalki moduan erabiltzen diren gehigarriak, besteak beste [7]. Era horretan, mikroplastikoek toxikoak izan daitezkeen kutsatzaile kimikoen garraiatzaile-lana bete dezakete itsasoan. Kutsatzaile horien artean, kutsatzaile organikoak (bisfenol A, ftalatoak), metal astunak (aluminioa, kobrea, zilarra, zinka, beruna, burdina eta manganesoa) edo pestizidak (dikloro difenil trikloroetanoa) adsorba ditzakete mikroplastikoek [23, 26]. Mikroplastikoak toxikoak diren kutsatzaile kimikoekin batera irensten dituzten organismoek ezin dituzte haiek deskonposatu, entzima-bideak falta baitzaizkie, eta, beraz, haien ehunetan metatzen dira eta itsasoko sare trofikoan zehar transferitzen dira. Baina sare trofiko honetan gertatzen den transferentziaren eta biohanditzearen ikerketa oso konplexua da, maila trofiko anitzaz eta harrapakaritza-erla- 
zio kopuru handiaz osatuta baitago. Ikerketa batzuen arabera, mikroplastikoen transferentziaren eraginkortasuna kutsatzaileen eskuragarritasunaren eta organismoen barnean ematen duten denboraren menpe egongo litzateke [19]. Diepens-ek eta Koelmans-ek 2018an [9] mikroplastikoen sare trofikoan zeharreko transferentziaren simulazio teorikoa egin zuten eredu teoriko bat erabiliz, eta ondorioztatu zuten kutsatzaile organikoen biohanditzea kutsatzaile motaren eta irentsitako mikroplastikoaren kantitatearen menpe zegoela.

Konposatu toxikoak dauzkaten mikroplastikoak sare trofikoan metatzeak irensten dituzten itsas organismoei efektu kaltegarri sorta zabala eragiteko ahalmen potentzial handia duela frogatu da [26]. Mikroplastikoen kontsumoak efektu mekanikoak eta kimikoak eragin ditzake itsas organismoengan [5]. Digestio-traktuaren buxadura gerta daiteke, edota higikortasuna oztopatzea polimeroak kanpoko azalari atxikitzen bazaizkio. Hantura, estres hepatikoa, hazkuntzaren jaistea edo asaldura endokrinoak ere izan daitezke mikroplastikoen toxizitatearen ondorio ikusgarriak [5].

\section{MIKROPLASTIKOEN GAINAZALAREN KOLONIZAZIOA}

Mikroplastikoek, beren nonahikotasunari esker eta gainazalean materia organikoa adsorbatzeko gaitasunari esker, biopelikulak sortzen dituzten mikroorganismoentzat habitat berria dira. Txoko ekologiko berri horri «plastisfera» deritzo [61]. Plastisferaren kolonizazioa, plastiko motaren, tamainaren eta adinaren, korronteen, tenperaturaren eta geografiaren arabera zehaztuta egongo da [62-64]. Biopelikula horiek mikroorganismokomunitate konplexuz, dibertsoz eta dinamikoz osatuta daude [65]. Komunitate horiek berezko mikroorganismoek berek ekoiztutako zelulaz kanpoko substantzia polimerikoz osatutako matrize batean murgilduta daude [8].

Egile askok plastisferan eransten diren mikroorganismo-komunitateak (bakterioak, onddoak eta protistoak) eta ur-zutabeko edo materia organiko partikulatuan aurkitu ohi direnak desberdinak direla behatu dute [66-70]. Hala ere, komunitate horiek, berezko mikroorganismoek osatzen duten kide guztiek, ez dute zertan zuzenki mikroplastikoaren biodegradazioarekin erlazionatuta egon. Horrela, kometabolismoa aurrera eramaten duten bakterioak han aurkitzen dira, biodegradatzaileen produktuak erabiliz hazten direnak, haiek mikroplastikoak degradatzeko gai ez izan arren. Bakterioen dentsitateak mikroplastikoetan altuak direnez, protistoak ere agertzen dira, eta harrapakaritzarako gune aktibo bilakatzen dira.

Bestalde, biopelikuladun mikroplastikoek, mikroorganismo patogenoen edota biotoxinen hedapenarekin erlazionatuta egon litezkeela ikusi da. Horrela, sakabanatzeko ahalmenaren ondorioz, mikroplastikoek bakterio pa- 
togenoen (Vibrio) [61, 71, 72], eukarioto patogenoen (Ephelota) [68] edo dinoflagelatu kaltegarrien (Ostreopsis, Coolia, Alexandrium) [73] bektorelana egin dezakete. Korronteen bidez ozeanoetan zehar gertatzen den mikroplastikoen garraioak mikroorganismo-komunitateen egituran eta banaketa geografikoan eragin lezake, bai eta ur-sistemen osasungarritasunean ere.

Biopelikulen eraketak mikroplastikoetan mikroorganismo horien aniztasun metabolikoan eta funtzionalean ere eragin lezake. Biopelikulak, han murgilduta agertzen diren bakterioak elkarrengandik hurbil dauden heinean, geneen transferentzia horizontalerako ingurugiro aproposak suertatzen dira. Bakterioek transferi ditzaketen geneen artean, degradazio-bide desberdinekin erlazionatutako geneak egon daitezke [74]. Mikroorganismo heterotrofoek materia organikoaren degradazioan eta sare trofikoan zeharreko transferentzian paper garrantzitsua betetzen dutenez gero [75], geneen elkartruke horrek ondorio ekologiko garrantzitsuak izan ditzake. Gainera, antibiotikoen aurkako erresistentziarekin edota determinatzaile patogenikoekin erlazionatutako geneen hedapenean ere parte har dezake geneen transferentzia horizontal horrek [8,9], zeinak osasun publikoan ondorio zuzenak ekar ditzakeen.

Mikroplastikoek eragindako kutsaduragatik, eta mikroorganismo-komunitateen konposizioa eta funtzioa aldatzeko duten gaitasunagatik, mikroplastikoek ozeanoetako karbonoaren zikloan eragiteko potentziala izango lukete eskala globalean $[12,13]$. Inpaktu hori kostaldeko eskualdeetan are handiagoa izan liteke, non bai mikroorganismoen jarduera bai mikroplastikoen kutsadura-maila ozeano irekian baino altuagoak diren.

\section{MIKROORGANISMOEN BIDEZKO BIODEGRADAZIOA}

Itsas uretan aurkitzen diren plastikoak tamainan, forman, dentsitate espezifikoan eta konposizio kimikoan desberdintzen diren partikulez osatuta daude [76]. Polimeroaren ezaugarri horiek eragina dute beren degradazioan. Plastikoa itsas uretan flotatzen dagoen bitartean, ultramore (UM) erradiazioa degradatzen hasiko da eta gradualki haien osotasuna galduz joango da [77]. Oso degradatuta dauden plastikoak hauskor bilakatzen dira eta zatietan deskonposatzen dira, eta mikroplastikoak askatzen dituzte. Zatiketa horregatik, mikroplastikoen ekoizpena eraginkorragoa izaten da kostaldeko itsas uretan ur irekietan baino, kostaldean altuagoak direlako UM erradiazioaren intentsitatea, olatuen abrasio fisikoa, oxigenoaren eskuragarritasuna [23] eta turbulentzia [78]. Behin zati horiek ingurumen sakonagoetan murgiltzen direnean, tenperatura hotzek eta UM erradiazioaren intentsitate txikiek deskonposizioa motelagoa izatea eragiten dute [22]. Sarritan begi-bistaz ikusezinak diren zatiek degradazio gehigarria jasan deza- 
kete, mikroorganismoek bideratutako biodegradazioaren bidez gehienetan. Mikroorganismoek entzimen bidez polimero konplexuak despolimerizatzen dituzte, hau da, barneratzeko errazagoak diren kate laburretan edo molekula txikiagoetan deskonposatzen dituzte. Baldintza idealetan, polimeroaren karbono zati bat mikroorganismoen biomasa bilakatuko da, eta gainerakoa biogas bihurtuko da, $\mathrm{CO}_{2}$-a ingurumen-baldintza oxigenikoen kasuan [79]. Polimeroaren karbono organiko guztia degradatzen denean, mineralizazio osoa gertatu dela esaten da.

Lignina [80], kitina [81], kitosanoa [82] edo substantzia humikoak eta fulbikoak [83] bezalako polimero natural gehienak mineralizatzeko sentikorrak dira itsasoan. Hala ere, gutxi dira guztiz mineraliza daitezkeen plastikoak, edo gutxienez denbora motzean (egun edo aste batzuetan) degrada daitezkeenak. Mikroplastiko gehienek hamarkadak edo mendeak behar dituzte degradatzeko, eta hori dela eta, ingurumenean metatzeko joera dute [17]. Polietilenoari eta polipropilenoari egonkortasuna ematen dieten karbono-kate luzeek eta hidrofoboek, polietileno tereftalatoaren eraztun aromatikoek edo poliestirenoaren estireno-monomero hidrofobikoek polimero horien biodegradazioa eragozten dute [65].

Mikroorganismoek ekoiztutako entzima askok (oxigenasak, lipasak, esterasak, despolimerasak, eta hainbat gehiago) polimero natural askoren degradazioa errazten dute, eta haietako batzuek polimero sintetikoak apurtzeko jarduera ere erakusten dute. Hori dela eta, azken urteetan mikroplastiko desberdinen biorremediazio eraginkorra burutzeko gai diren mikroorganismoen isolamendurako eta identifikaziorako lan esperimental ugari egin dira (1. taula). Horietan ikusi da Rhodococcus eta Bacillus bakterio generoko espezie batzuek 40 eguneko inkubazioan polipropilenoaren pisuan galerak (\%6,4 eta \%4, hurrenez hurren) eragiteko gai direla [84]. Montazer-rek eta haren kolaboratzaileek 2018an [85], Acinetobacter sp. eta Sphingobacterium sp. 4 astean polietilenozko mintz baten pisua \%26,8an eta \%6,3an hurrenez hurren erreduzitzeko gai zirela ere frogatu zuten. Kasu horietan guztietan, mikroskopia elektronikoa eta infragorrien mikroskopia erabiliz, mikroplastikoen gainazaletan ikusitako aldaketa estrukturalek eta morfologikoek berretsi zuten polimeroaren biodegradazioa. Oraintsuago, ikusi dute Micrococcus sp. eta Cupriavidus sp. ere polietilenoa degradatzeko gai direla (\%18,9 eta \%33,7, 21 egunean, hurrenez hurren) eta, aldi berean, polihidroxialkanoato polimero biodegradagarrietara biokonbertsioa egiteko gai direla [86].

Ur-sistema naturaletan, tenperatura, mantenugaien eskuragarritasuna edo harrapakaritza bezalako faktore askok eragin handia daukate mikroorganismoen aktibitatean. Hortaz, botiletan konfinatutako mikroorganismoekin eta baldintza esperimentaletan lortutako biodegradazio-tasak naturan gertatzen diren jardueretatik urrun egon daitezke. Zentzu horretan, beharrezkoa da informazio gehiago plastiko hauek guztiz biodegradatzeko gai 
diren mikroorganismoei buruz eta in situ eta baldintza naturaletan gertatutako biodegradazioari buruz.

\section{ONDORIOAK}

Jatorri eta konposizio desberdineko mikroplastikoen presentzia gero eta handiagoa da munduko itsaso eta ozeano guztietan, bira ozeanikoetan mikroplastiko horien kontzentrazioa bereziki nabarmena izanik. Mikroplastikoak ezin direnez era errazean degradatu, ingurumenean metatzeko joera dute. Egoera horretan, ozeano guztietan gertatzen ari den mikroplastikoen kopuruaren handipenak dakarren inpaktu ekologikoa eta toxikologikoa ebaluatzeko eta geldiarazteko premia dago.

Mikroplastikoak gainazal ezin hobeak dira mikroorganismo komunitate espezifikoen ezarpenerako eta biopelikulen eraketarako, eta, hortaz, zeregin garrantzitsua dute plastikozko mikropartikulen eta materia organikoaren hondoratzearen modulazioan, bai eta ur-sistemetako mikroorganismoen metabolismoaren eta konposizioaren aldaketan ere. Era horretan, mikroplastikoen nonahikotasunak inpaktua izan lezake mikroorganismoen funtzioan eta karbonoaren ziklo biogeokimiko globalean, oraindik magnitudea ezagutzen ez den arren.

Era berean, mikroplastikoek sare trofikoan metatzeko gaitasuna duten heinean, itsasoko maila trofiko desberdinetan ere ondorioak ekar ditzakete, mikroplastikoak irensten dituzten organismoengan eragiten dituzten efektu kaltegarri zuzenak direla eta. Gainera, mikroplastikoek patogenoen, biotoxinen eta gehigarri toxikoen garraioa fabora lezakete, bai eta antibiotikoekiko erresistentziarekin erlazionatutako geneen transferentzia sustatu ere. Faktore horiek ur-sistemen osasungarritasunean izan ditzaketen ondorioak ezagutzea beharrezkoa suertatzen da.

Ozeanoetako mikroplastikoen kutsadura murrizteko, ezinbestekoa da haiek ezabatzeko metodo eraginkorrak garatzea. Azken urteetan egindako ikerketek erakusten dute mikroplastikoak biodegradatzeko gai diren mikroorganismo asko daudela, ingurumenean inpaktu kaltegarririk eragiten ez dutenak, eta, beraz, mikroplastikoen kutsadura murrizteko funtsezko rola izan dezaketenak. Hala ere, mikroorganismo desberdinen degradaziorako gaitasunen gainean gutxi ezagutzen da. Mikroplastiko mota desberdinak guztiz degradatzeko gai diren mikroorganismoen identifikazioa eta karakterizazioa eta biodegradaziorako baldintzarik onenak zeintzuk diren sakonago ikertu beharreko arloak dira, bai eta baldintza naturaletan degradazio-tasak azkartzeko moduak ere. 
1. taula. Polietilenoz (PE), polipropilenoz (PP), poliestirenoz (PS), polietileno tereftalatoz (PET) eta binilo polikloruroz (PVC) osatutako mikroplastikoak degradatzeko gai diren bakterioak eta onddoak.

\begin{tabular}{|c|c|c|}
\hline Mikroorganismoa & Plastiko mota & Erreferentzia(k) \\
\hline \multicolumn{3}{|l|}{ BAKTERIOAK } \\
\hline Achromobacter sp. & PE, PVC & {$[87,88]$} \\
\hline Acinetobacter sp. & PE & {$[85,89]$} \\
\hline Aneurinibacillus sp. & PE, PP & {$[90]$} \\
\hline Azotobacter sp. & PS & [91] \\
\hline Bacillus sp. & PE, PET, PS, PP, PVC & {$[84,92-101]$} \\
\hline Brevibacillus sp. & PE, PP & {$[84,89,90,102]$} \\
\hline Citrobacter sp. & PE & {$[85]$} \\
\hline Comamonas sp. & $\mathrm{PE}$ & [103] \\
\hline Cupriavidus sp. & PE & {$[86]$} \\
\hline Delftia sp. & $\mathrm{PE}$ & {$[85,103]$} \\
\hline Enterobacter sp. & PE & {$[96,104]$} \\
\hline Exiguobacterium sp. & PS & {$[97,105]$} \\
\hline Ideonella sp. & PET & [106] \\
\hline Kocuria sp. & $\mathrm{PE}$ & [95] \\
\hline Lysinibacillus sp. & $\mathrm{PE}$ & [107] \\
\hline Microbacterium sp. & PS & [94] \\
\hline Micrococcus sp. & $\mathrm{PE}$ & [86] \\
\hline Nocardia $\mathrm{sp}$. & PET & [108] \\
\hline Ochrobactrum sp. & $\mathrm{PE}$ & {$[85]$} \\
\hline Paenibacillus sp. & PE, PS & {$[94,101]$} \\
\hline Pantoea sp. & PE & [104] \\
\hline Pseudomonas sp. & PE, PET, PS, PVC & {$[86,87,89,94,100,109,110]$} \\
\hline Rhodococcus sp. & PE, PS, PP & {$[107,111-114]$} \\
\hline Serratia $\mathrm{sp}$. & $\mathrm{PE}$ & [98] \\
\hline Sphingobacterium sp. & $\mathrm{PE}$ & {$[85]$} \\
\hline Staphylococcus sp. & PS & {$[97]$} \\
\hline Stenotrophomonas $\mathrm{sp}$. & $\mathrm{PE}$ & {$[85,98,103]$} \\
\hline Streptococcus sp. & PS & [97] \\
\hline Thermobifida sp. & PET & {$[115]$} \\
\hline Thermomonospora sp. & PET & [116] \\
\hline \multicolumn{3}{|l|}{ ONDDOAK } \\
\hline Alternaria sp. & PVC & {$[117]$} \\
\hline Aspergillus sp. & PE, PVC, PP & {$[117-120]$} \\
\hline Aureobasidium sp. & PVC & [117] \\
\hline Chaetomium sp. & $\mathrm{PE}$ & [119] \\
\hline Cladosporium sp. & PVC & [117] \\
\hline Engyodontium sp. & PP & {$[121]$} \\
\hline Emericella $\mathrm{sp}$. & PVC & {$[117]$} \\
\hline Epicoccum sp. & PVC & {$[117]$} \\
\hline Fusarium sp. & PET & {$[116,122]$} \\
\hline Gliocladium sp. & $\mathrm{PE}$ & [118] \\
\hline Humicola sp. & PET & [110] \\
\hline Kluyveromyces sp. & PVC & {$[117]$} \\
\hline Lasiodiplodia sp. & PE, PP & [120] \\
\hline Paecilomyces sp. & PE, PVC & {$[117,120]$} \\
\hline Penicillium sp. & PE, PET, PS, PVC & {$[117,118,123,124]$} \\
\hline Phaeococcomyces sp. & PVC & [117] \\
\hline Phanerochaete sp. & PP & [121] \\
\hline Rhodotorulla sp. & PVC & {$[117]$} \\
\hline Taphrina sp. & PVC & {$[117]$} \\
\hline Thanatephorous sp. & PVC & {$[117]$} \\
\hline Trametes $\mathrm{sp}$. & $\mathrm{PE}$ & [114] \\
\hline Zalerion sp. & $\mathrm{PE}$ & {$[125]$} \\
\hline
\end{tabular}


Etorkizunari begira, denbora-tarte laburrean mikroplastiko desberdinak guztiz mineralizatzeko gai diren mikroorganismoen erabilpenak onura ekologiko askotarikoak ekar ditzake. Alde batetik, mikroorganismo horiek erreminta erabilgarriak suerta daitezke partikula plastikoekin kutsatutako ur-sistemen in situ biorremediazioan erabiltzeko. Horrez gain, araztegietako uraren tratamenduan ere erabiltzea interesgarria bilakatuko litzateke, ozeanoetara efluenteen eta lohien bidez heltzen diren mikroplastikoen kantitatea murriztuko bailitzateke. Gainera, prozesu horien bitartez, polietileno tereftalato bezalako plastikoak berreskuratu eta berrerabili ahal izango balira, plastiko berrien ekoizpena murriztuko litzateke, bai eta petroliotik eratorrietako materialen erabilpena aurreztu ere.

\section{BIBLIOGRAFIA}

[1] PLASTICS EUROPE. 2018. Plastics - the facts 2018: an analysis of European plastic production, demand and waste data for 2018. Brussels, Belgium.

[2] JAMBECK, J.R., GEYER, R., WILCOX, C., SIEGLER, T.R., PERRYMAN, M., ANDRADY, A. et al. 2015. «Plastic waste inputs from land into the ocean». Science, 347, 768-771.

[3] ERIKSEN, M., LEBRETON, L.C.M., CARSON, H.S., THIEL, M., MOORE, C.J., BORERRO, J.C. et al. 2014. «Plastic pollution in the world's oceans: more than 5 trillion plastic pieces weighing over 250,000 tons afloat at sea». PLOS ONE, 9(12), e111913.

[4] GEYER, R., JAMBECK, J.R. eta LAW, K.L. 2017. «Production, use, and fate of all plastics ever made». Science Advances, 3, e1700782.

[5] GESAMP. 2015. «Sources, fate and effects of microplastics in the marine environment: a global assessment». IMO/FAO/UNESCO-IOC/UNIDO/ WMO/IAEA/UN/UNEP/UNDP, Joint Group of Experts on the Scientific Aspects of Marine Environmental Protection Reports and Studies.

[6] LUSHER, A. 2015. Microplastics in the Marine Environment: Distribution, Interactions and Effects. In: Bergmann M., Gutow L., Klages M. (eds.) Marine Anthropogenic Litter. Springer International Publishing, Switzerland.

[7] BAKIR, A., ROWLAND, S.J. eta THOMPSON, R.C. 2014. «Enhanced desorption of persistent organic pollutants from microplastics under simulated physiological conditions». Environmental Pollution, 185, 16-23.

[8] FLEMMING, H.C. 2016. «EPS - then and now». Microorganisms, 4, 41.

[9] BALCÁZAR, J.L., SUBIRATS, J. eta BORREGO, C.M. 2015. «The role of biofilms as environmental reservoirs of antibiotic resistance». Frontiers in Microbiology, 6(20), 1216.

[10] HOLLMAN, P.C.H., BOUWMEESTER, H. eta PETERS, R.J.B. 2013. «Microplastics in the aquatic food chain: sources, measurements, occurrence and 

hedapena eta mikroorganismoen bidezko biodegradazioa ozeanoetan

potential health risks». RIKILT Report 2013.003, Wageningen University and Research Centre, Herbeherak.

[11] DIEPENS, N.J. eta KOELMANS, A.A. 2018. «Accumulation of plastic debris and associated contaminants in aquatic food webs». Environmental Science and Technology, 52, 8510-8520.

[12] ROMERA-CASTILLO, C., PINTO, M., LANGER, T.M., ÁLVAREZ-SALGADO, X.A. eta HERNDL, G.J. 2018. «Dissolved organic carbon leaching from plastics stimulates microbial activity in the ocean». Nature Communications, 9, 1430.

[13] ARIAS-ANDRES, M., ROJAS-JIMENEZ, K. eta GROSSART, H.P. 2019. «Collateral effects of microplastic pollution on aquatic microorganisms: An ecological perspective». Trends in Analytical Chemistry, 112, 234-240.

[14] ROCHMAN, C.M., HOH, E., KUROBE, T. eta TEH, S.J. 2013. «Ingested plastic transfers hazardous chemicals to fish and induces hepatic stress». Scientific Reports, 3, 3263.

[15] THOMPSON, R.C., OLSEN, Y., MITCHELL, R.P., DAVIS, A., ROWLAND, S.J., JOHN, A.W.G. et al. 2004. «Lost at sea: where is all the plastic?». Science, 304(5672), 838.

[16] ROCHMAN, C.M. 2018. «Microplastics research-from sink to source». Science, 360(6384), 28-29.

[17] DERRAIK, J.G.B. 2002. «The pollution of the marine environment by plastic debris: a review». Marine Pollution Bulletin, 44(9), 842-852.

[18] MURPHY, F., EWINS, C., CARBONNIER, F. eta QUINN, B. 2016. «Wastewater treatment works (WwTW) as a source of microplastics in the aquatic environment». Environmental Science and Technology, 50(11), 5800-5808.

[19] MOORE, C.J. 2008. «Synthetic polymers in the marine environment: a rapidly increasing, long-term threat». Environmental Research, 108(2), 131139.

[20] LEBRETON, L.C.M., VAN DER ZWET, J., DAMSTEEG, J.W., SLAT, B., ANDRADY, A. eta REISSER, J. 2017. «River plastic emissions to the world's oceans». Nature Communications, $8,15611$.

[21] MOORE, C.J., MOORE, S.L., WEISBERG, S.B., LATTIN, G.L. eta ZELLERS, A.F. 2002. «A comparison of neustonic plastic and zooplankton abundance in southern California's coastal waters». Marine Pollution Bulletin, 44(10), 1035-1038.

[22] ANDRADY, A.L. 2011. «Microplastics in the marine environment». Marine Pollution Bulletin, 62, 1596-1605.

[23] COLE, M., LINDEQUE, P., HALSBAND, C. eta GALLOWAY, T.S. 2011. «Microplastics as contaminants in the marine environment: A review». Marine Pollution Bulletin, 62, 2588-2597.

[24] CASTAÑEDA, R.A., AVLIJAS, S., SIMARD, M.A. eta RICCIARDI, A. 2014. «Microplastic pollution in St. Lawrence River sediments». Canadian Journal of Fisheries and Aquatic Sciences, 71(12), 1767-1771. 
[25] GESAMP. 2015. «Microplastics in the ocean: a global assesment». IMO/ FAO/UNESCO-IOC/UNIDO/WMO/IAEA/UN/UNEP/UNDP, Joint Group of Experts on the Scientific Aspects of Marine Environmental Protection Reports and Studies.

[26] AUTA, H.S., EMENIKE, C.U. eta FAUZIAH, S.H. 2017a. «Distribution and importance of microplastics in the marine environment: a review of the sources, fate, effects, and potential solutions». Environment International, 102, 165-176.

[27] ENGLER, R.E. 2012. «The complex interaction between marine debris and toxic chemicals in the ocean». Environmental Science and Technology, 46(22), 12302-12315.

[28] REISSER, J., SHAW, J., HALLEGRAEFF, G., PROIETTI, M., BARNES, D.K.A., THUMS, M. et al. 2014. «Millimeter-sized marine plastics: a new pelagic habitat for microorganisms and invertebrates». PLoS One, 9(6), e100289.

[29] COLE, M., WEBB, H., LINDEQUE, P.K., FILEMAN, E.S., HALSBAND, C. eta GALLOWAY, T.S. 2014. «Isolation of microplastics in biota-rich seawater samples and marine organisms». Scientific Reports, 4, 4528.

[30] EERKES-MEDRANO, D., THOMPSON, R.C. eta ALDRIDGE, D.C. 2015. «Microplastics in freshwater systems: a review of the emerging threats, identification of knowledge gaps and prioritization of research needs». Water Research, 75, 63-82.

[31] ERIKSSON, C., BURTON, H., FITCH, S., SCHULZ, M. eta VAN DEN HOFF, J. 2013. «Daily accumulation rates ofmarine debris on sub-Antarctic island beaches». Marine Pollution Bulletin, 66(1-2), 199-208.

[32] CLAESSENS, M., VAN CAUWENBERGHE, L., VANDEGEHUCHTE, M.B. eta JANSSEN, C.R. 2013. «New techniques for the detection of microplastics in sediments and field collected organisms». Marine Pollution Bulletin, 70(1-2), 227-233.

[33] MOORE, C.J., LATTIN, G.L. eta ZELLERS, A.F. 2005. «Working ourway upstream: a snapshot of landbased contributions of plastic and other trash to coastalwaters and beaches of Southern California». Proceedings of the Plastic Debris Rivers to Sea Conference, Algalita Marine Research Foundation, California.

[34] BROWNE, M.A., CRUMP, P., NIVEN, S.J., TEUTEN, E., TONKIN, A., GALLOWAY, T. et al. 2011. «Accumulation of microplastic on shorelines worldwide: Sources and sinks». Environmental Science and Technology, 45(21), 9175-9179.

[35] WOODALL, L.C., SANCHEZ-VIDAL, A., CANALS, M., PATERSON, G.L.J., COPPOCK, R., SLEIGHT, V. et al. 2014. «The deep sea is a major sink for microplastic debris». Royal Society of Open Science, 1(4), 140317.

[36] OBBARD, R.W., SADRI, S., WONG, Y.Q., KHITUN, A.A., BAKER, I. eta THOMPSON, R.C. 2014. «Global warming releases microplastic legacy frozen in Arctic Sea ice». Earth's Future, 2(6), 315-320. 

hedapena eta mikroorganismoen bidezko biodegradazioa ozeanoetan

[37] ZARFL, C. eta MATTHIES, M. 2010. «Are marine plastic particles transport vectors for organic pollutants to the Arctic?». Marine Pollution Bulletin, 60(10), 1810-1814.

[38] KARL, D.M. 1999. "A sea of change: biogeochemical variability in the North Pacific Subtropical Gyre». Ecosystems, 2, 181-214.

[39] KAISER, J. 2010. «The dirt on ocean garbage patches». Science, 328, 1506.

[40] GOLDSTEIN, M.C., ROSENBERG, M. eta CHENG, L. 2012. «Increased oceanic microplastic debris enhances oviposition in an endemic pelagic insect». Biology Letters, 8(5), 817-820.

[41] LAW, K.L., MORÉT-FERGUSON, S., MAXIMENKO, N.A., PROSKUROWSKI, G., PEACOCK, E.E., HAFNER, J. et al. 2010. «Plastic accumulation in the North Atlantic subtropical gyre». Science, 329(5996), 1185-1188.

[42] ERIKSEN, M., MAXIMENKO, N., THIEL, M., CUMMINS, A., LATTIN, G., WILSON, S. et al. 2013. «Plastic pollution in the South Pacific subtropical gyre». Marine Pollution Bulletin, 68(1-2), 71-76.

[43] COLLIGNON, A., HECQ, J.H., GLAGANI, F., VOISIN, P., COLLARD, F. eta GOFFART, A. 2012. «Neustonic microplastic and zooplankton in the North Western Mediterranean Sea». Marine Pollution Bulletin, 64(4), 861864.

[44] NG, K.L. eta OBBARD, J.P. 2006. «Prevalence of microplastics in Singapore's coastal marine environment». Marine Pollution Bulletin, 52, 761-7.

[45] VAN SEBILLE, E., ENGLAND, M.H. eta FROYLAND, G. 2012. «Origin, dynamics and evolution of ocean garbage patches from observed surface drifters». Environmental Research Letters, 7, 044040.

[46] SUARIA, G. eta ALIANI, S. 2014. «Floating debris in the Mediterranean Sea». Marine Pollution Bulletin, 86(1-2),494-504.

[47] PORTER, A., LYONS, B.P., GALLOWAY, T.S. eta LEWIS, C. 2018. «Role of Marine Snows in Microplastic Fate and Bioavailability». Environmental Science and Technology, 52(12), 7111-7119.

[48] ZALASIEWICZ, J., WATERS, C.N., IVAR DO SUL, J.A., CORCORAN, P.L., BARNOSKY, A.D., CEARRETA, A. et al. 2016. «The geological cycle of plastics and their use as a stratigraphic indicator of the Anthropocene». Anthropocene, 13, 4-17.

[49] DOYLE, M.J., WATSON, W., BOWLIN, N.M. eta SHEAVLY, S.B. 2011. «Plastic particles in coastal pelagic ecosystems of the Northeast Pacific ocean». Marine Environmental Research, 71(1), 41-52.

[50] FRIAS, J.P.G.L., OTERO, V., eta SOBRAL, P. 2014. «Evidence of microplastics in samples of zooplankton from Portuguese coastal waters». Marine Environmental Research, 95, 89-95.

[51] LATTIN, G.L., MOORE, C.J., ZELLERS, A.F., MOORE, S.L., eta WEISBERG, S.B. 2004. "A comparison of neustonic plastic and zooplankton at different depths near the southern California shore». Marine Pollution Bulletin, 49(4), 291-294. 
[52] VON MOOS, N., BURKHARDT-HOLM, P., eta KÖHLER, A. 2012. «Uptake and effects of microplastics on cells and tissue of the blue mussel Mytilus edulis L. after an experimental exposure». Environmental Science and Technology, 46(20), 11327-11335.

[53] WINDSOR F.M., TILLEY, R.M., TYLER, C.R., ORMEROD, S.J. 2019. «Microplastic ingestion by riverine macroinvertebrates». Science of the Total Environment, 646, 68-74.

[54] FERrEIRA, P., FONTE, E., SOARES, M.E., CARVALHO, F. eta GUILHERMINO, L. 2016. «Effects of multi-stressors on juveniles of the marine fish Pomatoschistus microps: gold nanoparticles, microplastics and temperature». Aquatic Toxicology, 170, 89-103.

[55] NICASTRO, C.R., LO SAVIO, R., MCQUAID, C.D., MADEIRA, P., VALBUSA, U., AZEVEDO et al. 2018. «Plastic ingestion in aquatic-associated bird species in southern Portugal». Marine Pollution Bulletin, 126, 413-418.

[56] CARON, A.G.M., THOMAS, C.R., ARIEL, E., BERRY, K.L.E., BOYLE, S., MOTTI, C.A. et al. 2016. «Extraction and identification of microplastics from sea turtles: method development and preliminary results». Tropical Water Report, 1-37.

[57] FOSSI, M.C., MARSILI, L., BAINI, M., GIANNETTI, M., COPPOLA, D., GUERRANTI, C. et al. 2016. «Fin whales and microplastics: the Mediterranean Sea and the sea of Cortez scenarios». Environmental Pollution, 209, 68-78.

[58] KIM, J.S., LEE, H.J., KIM, S.K., eta KIM, H.J. 2018. «Global pattern of microplastics (MPs) in commercial food-grade salts: sea salt as an indicator of seawater MP pollution». Environmental Science and Technology, 52, 12819-12828.

[59] WRIGHT, S.L., THOMPSON, R.C., eta GALLOWAY, T.S. 2013. «The physical impacts of microplastics on marine organisms: A review». Environmental Pollution, 178, 483-492.

[60] LÖNNSTEDT, O.M. eta EKLÖV, P. 2016. «Environmentally relevant concentrations of microplastic particles influence larval fish ecology, ecotoxicology». Science, 352(6290), 1213-1216.

[61] ZETTLER, E.R., MINCER, T.J. eta AMARAL-ZETTLER, L.A. 2013. «Life in the «plastisphere»: microbial communities on plastic marine debris». Environmental Science and Technology, 47(13), 7137-7146.

[62] AMARAL-ZETTLER, L.A., ZETTLER, E.R., SLIKAS, B., BOYD, G.D., MELVIN, D.W., MORRALL, C.E. et al. 2015. «The biogeography of the plastisphere: implications for policy». Frontiers in Ecology and the Environment, 13(10), 541-546.

[63] OBERBECKMANN, S., OSBORN, A.M., eta DUHAIME, M.B. 2016. «Microbes on a bottle: substrate, season and geography influence community composition of microbes colonizing marine plastic debris». PLoS One, 11(8), e0159289.

[64] HARRISON, J.P., BOARDMAN, C., O'CALLAGHAN, K., DELORT, A.M., eta SONG, J. 2018. «Biodegradability standards for carrier bags and 

hedapena eta mikroorganismoen bidezko biodegradazioa ozeanoetan

plastic films in aquatic environments: a critical review». Royal Society Open Science, 5(5), 171792.

[65] JACQUIN, J., CHENG, J., ODOBEL, C., PANDIN, C., CONAN, P., PUJOPAY, M. et al. 2019. «Microbial ecotoxicology of marine plastic debris: A review on colonization and biodegradation by the "Plastisphere"». Frontiers in Microbiology, 10, 865.

[66] BRYANT, J.A., CLEMENTE, T.M., VIVIANI, D.A., FONG, A.A., THOMAS, K.A., KEMP, P. et al. 2016. «Diversity and activity of aommunities inhabiting plastic debris in the North Pacific gyre». mSystems, 1(3), e00024-16.

[67] KETTNER, M.T., ROJAS-JIMENEZ, K., OBERBECKMANN, S., LABRENZ, M., eta GROSSART, H.P. 2017. «Microplastics alter composition of fungal communities in aquatic ecosystems». Environmental Microbiology, 19(11), 4447-4459.

[68] DEBROAS, D., MONE, A., eta TER HALlE, A. 2017. «Plastics in the North Atlantic garbage patch: a boat-microbe for hitchhikers and plastic degraders». Science of the Total Environment, 599, 1222-1232.

[69] OGONOWSKI, M., MOTIEI, A., ININBERGS, K., HELL, E., GERDES, Z., UDEKWU, K.I. et al. 2018. «Evidence for selective bacterial community structuring on microplastics». Environmental Microbiology, 20(8), 27962808.

[70] MIAO, L., WANG, P., HOU, J., YAO, Y., LIU, Z., LIU, S. et al. 2019. «Distinct community structure and microbial functions of biofilms colonizing microplastics». Science of the Total Environment, 650, 2395-2402.

[71] De TENDER, C.A., DEVRIESE, L.I., HAEGEMAN, A., MAES, S., RUTTINK, T. eta DAWYNDT, P. 2015. «Bacterial community profiling of plastic litter in the Belgian part of the North Sea». Environmental Science and Technology, 49(16), 9629-9638.

[72] KIRSTEIN, I.V., KIRMIZI, S., WICHELS, A., GARIN-FERNANDEZ, A., ERLER, R., LÖDER, M. et al. 2016. «Dangerous hitchhikers? Evidence for potentially pathogenic Vibrio spp. on microplastic particles». Marine Environmental Research, 120, 1-8.

[73] MASÓ, M., GARCÉS, E., PAGÈS, F., eta CAMP, J. 2003. «Drifting plastic debris as a potential vector for dispersing Harmful Algal Bloom (HAB) species». Scientia Marina, 67, 107-111.

[74] ARIAS-ANDRES, M., KLUMPER, U., ROJAS-JIMENEZ K., eta GROSSART, H.P. 2018. «Microplastic pollution increases gene exchange in aquatic ecosystems». Environmental Pollution, 237, 253-261.

[75] PERNTHALER, J. eta AMANN, R. 2005. «Fate of heterotrophic microbes in pelagic habitats: focus on populations». Microbiology and Molecular Biology Reviews, 69(3), 440-461.

[76] DUIS, K. eta COORS, A. 2016. «Microplastics in the aquatic and terrestrial environment: sources (with a specific focus on personal care products), fate and effects». Environmental Sciences Europe, 28(2). 
[77] PEGRAM, J.E. eta ANDRADY, A.L. 1989. «Outdoor weathering of selected polymeric materials under marine exposure conditions». Polymer Degradation and Stability, 26(4), 333-345.

[78] BARNES, D.K.A, GALGANI, F., THOMPSON, R.C. eta BARLAZ, M. 2009. «Accumulation and fragmentation of plastic debris in global environments». Philosophical Transactions of the Royal Society B, 364(1526), 1985-1998.

[79] MOHEE, R., UNMAR, G.D., MUDHOO, A. eta KHADOO, P. 2008. «Biodegradability of biodegradable/degradable plastic materials under aerobic and anaerobic conditions». Waste Management. 28(9), 1624-1629.

[80] MARTINEZ, A.T., SPERANZA, M., RUIZ-DUENAS, F.J., FERREIRA, P., CAMARERO, S., GUILLEN, F. et al. 2005. «Biodegradation of lignocellulosics: microbial chemical, and enzymatic aspects of the fungal attack of lignin». International Microbiology, 8(3), 195-204.

[81] POULICEK, M. eta JEUNIAUX, C. 1991. «Chitin biodegradation in marine environments: An experimental approach». Biochemical Systematics and Ecology, 19(5), 385-394.

[82] ANDRADY, A.L., PEGRAM, J.E. eta OLSON, T.M. 1992. «Research and development of two marine-degradable biopolymers». Technical Report A150452 David Taylor Research Center, US Department of the Navy.

[83] HOFRICHTER, M. 2002. «Review: lignin conversion by manganese peroxidase (MnP)». Enzyme and Microbial Technology, 30(4), 454-466.

[84] AUTA, H.S., EMENIKE, C.U., JAYANTHI, B. eta FAUZIAH, S.H. 2018. «Growth kinetics and biodeterioration of polypropylene microplastics by $B a$ cillus sp. and Rhodococcus sp. isolated from mangrove sediment». Marine Pollution Bulletin, 127, 15-21.

[85] MONTAZER, Z., HABIBI-NAJAFI, M.B., MOHEBBI, M. eta OROMIEHEI, A. 2018. «Microbial degradation of UV-pretreated low-density polyethylene films by novel polyethylene-degrading bacteria isolated from plastic- dump soil». Journal of Polymers and the Environment, 26(9), 36133625.

[86] MONTAZER, Z., HABIBI-NAJAFI, M.B. eta LEVIN D.B. 2019. «Microbial degradation of low-density polyethylene and synthesis of polyhydroxyalkanoate polymers». Canadian Journal of Microbiology, 65(3), 224-234.

[87] DAS, G., BORDOLOI, N.K., RAI, S.K., MUKHERJEE, A.K. eta KARAK, N. 2012. «Biodegradable and biocompatible epoxidized vegetable oil modified thermostable poly(vinyl chloride): thermal and performance characteristics post biodegradation with Pseudomonas aeruginosa and Achromobacter sp». Journal of Harzardous Materials, 209-210, 434-442.

[88] KOWALCZYK, A., CHYC, M., RYSZKA, P. eta LATOWSKI, D. 2016. «Achromobacter xylosoxidans as a new microorganism strain colonizing high-density polyethylene as a key step to its biodegradation». Environmental Science and Pollution Research, 23(11), 11349-11356.

[89] PRAMILA, R. 2012. «Brevibacillus parabrevis, Acinetobacter baumannii and Pseudomonas citronellolis - Potential candidates for biodegradation of 

hedapena eta mikroorganismoen bidezko biodegradazioa ozeanoetan

low density polyethylene (LDPE)». Journal Bacteriology Research, 4(1), 9-14.

[90] SKARIYACHAN, S., PATIL, A.A., SHANKAR, A., MANJUNATH, M., BACHAPPANAVAR, N. eta KIRAN, S. 2018. «Enhanced polymer degradation of polyethylene and polypropylene by novel thermophilic consortia of Brevibacillus sps. and Aneurinibacillus sp. screened from waste management landfills and sewage treatment plants». Polymer Degradation and Stability, 149, 52-68.

[91] NAKAMIYA, K., SAKASITA, G., OOI, T. eta KINOSHITA, S. 1997. «Enzymatic degradation of polystyrene by hydroquinone peroxidase of Azotobacter beijerinckii HM121». Journal of Fermentation and Bioengineering, 84(5), 480-482.

[92] OIKAWA, E., LINN, K.T., ENDO, T., OIKAWA, T. eta ISHIBASHI, Y. 2003. «Isolation and characterization of polystyrene degrading microorganisms for zero emission treatment of expanded polystyrene». Environmental Engeenering Research, 40, 373-379.

[93] SUDHAKAR, M., DOBLE, M., MURTHY, P.S. eta VENKATESAN, R. 2008. «Marine microbe-mediated biodegradation of low- and high-density polyethylenes». International Biodeterioration and Biodegradation, 61(3), 203-213.

[94] ATIQ, N., AHMED, S., ALI, M.I., SAADIA, L., AHMAD, B. eta ROBSON, G. 2010. «Isolation and identification of polystyrene biodegrading bacteria from soil». African Journal of Microbiology Research, 4(14), 15371541.

[95] HARSHVARDHAN, K. eta JHA, B. 2013. «Biodegradation of low-density polyethylene by marine bacteria from pelagic waters, Arabian Sea, India». Marine Pollution Bulletin, 77(1-2), 100-106.

[96] YANG, J., YANG, Y., WU, W.M., ZHAO, J. eta JIANG, L. 2014. «Evidence of polyethylene biodegradation by bacterial strains from the guts of plastic-eating waxworms». Environmental Science and Technology, 48(23), 13776-13784.

[97] ASMITA, K., SHUBHAMSINGH, T., TEJASHREE, S., ROAD, D. eta ROAD, D. 2015. «Isolation of plastic degrading micro-organisms from soil samples collected at various locations in Mumbai, India». International Research Journal of Environment Sciences, 4(3), 77-85.

[98] JAMIL, S.U.U., ZADA, S., KHAN, I., SAJJAD, W., RAFIQ, M., SHAH, A.A. et al. 2017. «Biodegradation of polyethylene by bacterial strains isolated fromKashmir Cave, Buner, Pakistan». Journal of Cave and Karst Studies, 79(1), 73-80.

[99] NOVOTNÝ, È., MALACHOVÁ, K., ADAMUS, G., KWIECIEÑ, M., LOTTI, N., SOCCIO, M. et al. 2018. «Deterioration of irradiation/high-temperature pretreated, linear lowdensity polyethylene (LLDPE) by Bacillus amyloliquefaciens». International Biodeterioration and Biodegradation, 132, 259-267. 
[100] GIACOMUCCI, L., RADDADI, N., SOCCIO, M., LOTTI, N. eta FAVA, F. 2019. «Polyvinyl chloride biodegradation by Pseudomonas citronellolis and Bacillus flexus». New Biotechnology, 52, 35-41.

[101] PARK, S.Y. eta KIM, C.G. 2019. «Biodegradation of micro-polyethylene particles by bacterial colonization of a mixed microbial consortium isolated from a landfill site». Chemosphere, 222, 527-533.

[102] HADAD, D., GERESH, S. eta SIVAN, A. 2005. «Biodegradation of polyethylene by the thermophilic bacterium Brevibacillus borstelensis». Journal of Applied Microbiology, 98(5), 1093-1100.

[103] PEIXOTO, J., SILVA, L.P. eta KRÜGER, R.H. 2017. «Brazilian Cerrado soil reveals an untapped microbial potential for unpretreated polyethylene biodegradation». Journal of Hazardous Materials, 324, 634-644.

[104] SKARIYACHAN, S., MANJUNATHA, V., SULTANA, S., JOIS, C., BAI, V. eta VASIST, K.S. 2016. «Novel bacterial consortia isolated from plastic garbage processing areas demonstrated enhanced degradation for low density polyethylene». Environmental Science and Pollution Research, 23(18), 18307-18319.

[105] CHAUHAN, D., AGRAWAL, G., DESHMUKH, S., ROY, S.S. eta PRIYADARSHINI, R. 2018. «Biofilm formation by Exiguobacterium sp. DR11 and DR14 alter polystyrene surface properties andinitiate biodegradation». Royal Society of Chemistry Advances, 8(66),37590-37599.

[106] YOSHIDA, S., HIRAGA, K., TAKEHANA, T., TANIGUCHI, I., YAMAJI, H., MAEDA, Y. et al. 2016. «A bacterium that degrades and assimilates poly(ethylene terephthalate)». Science, 351(6278), 1196-1199.

[107] ESMAEILI, A., POURBABAEE, A.A., ALIKHANI, H.A., SHABANI, F. eta ESMAEILI, E. 2013. «Biodegradation of low-density polyethylene (LDPE) by mixed culture of Lysinibacillus xylanilyticus and Aspergillus niger in soil». PLoS One, 8(9), e71720.

[108] SHARON, C. eta SHARON, M. 2012. «Studies on biodegradation of polyethylene terephthalate: a synthetic polymer». Journal of Microbiology and Biotechnology Research, 2(2), 248-257.

[109] WARD, P.G., GOFF, M., DONNER, M., KAMINSKY, W. eta O'CONNOR, K.E. 2006. «A two step chemo-biotechnological conversion of polystyrene to a biodegradable thermoplastic». Environmental Science and Technology, 40(7), 2433-2437.

[110] RONKVIST, A.M., XIE, W., LU, W. eta GROSS, R.A. 2009. «Cutinasecatalyzed hydrolysis of poly(ethylene terephthalate)». Macromolecules, 42(14), 5128-5138.

[111] SIVAN, A., SZANTO, M. eta PAVLOV, V. 2006. «Biofilm development of the polyethylene-degrading bacterium Rhodococcus ruber». Applied Microbiology and Biotechnology, 72(2), 346-352.

[112] MOR, R. eta SIVAN, A. 2008. «Biofilm formation and partial biodegradation of polystyrene by the actinomycete Rhodococcus ruber». Biodegradation, 19(6), 851-858. 

hedapena eta mikroorganismoen bidezko biodegradazioa ozeanoetan

[113] FONTANELLA, S., BONHOMME, S., BRUSSON, J.M., PITTERI, S., SAMUEL, G., PICHON G. et al. 2013. «Comparison of biodegradability of various polypropylene films containing additives based on $\mathrm{Mn}, \mathrm{Mn} / \mathrm{Fe}$ or Co». Polymer Degradation and Stability, 98(4), 875-884.

[114] SANTO, M., WEITSMAN, R. eta SIVAN, A. 2013. «The role of the copper-binding enzyme - laccase - in the biodegradation of polyethylene by the actinomycete Rhodococcus ruber». International Biodeterioration and Biodegradation, 84, 204-210.

[115] MÜllER, R.J., SCHRADER, H., PROFE, J., DRESLER, K. eta DECKWER, W.D. 2005. «Enzymatic degradation of Poly(ethylene terephthalate): rapid hydrolyse using a hydrolase from T. fusca». Macromolecular Rapid Communications, 26(17), 1400-1405.

[116] ALISCH, M., FEUERHACK, A., MÜLLER, H., MENSAK, B., ANDREAUS, J. eta ZIMMERMANN, W. 2004. «Biocatalytic modification of polyethylene terephthalate fibres by esterases from actinomycete isolates». Biocatalysis and Biotransformation, 22(5-6), 347-351.

[117] WEBB J.S., NIXON M., EASTWOOD I.M., GREENHALGH M., ROBSON G.D. eta HANDLEY P.S. 2000. «Fungal colonization and biodeterioration of plasticized polyvinylchloride». Applied and Environmental Microbiology, 66(8), 3194-3200.

[118] MANZUR, A., LIMÓN-GONZÁLEZ, M. eta FAVELA-TORRES, E. 2004. «Biodegradation of physicochemically treated LDPE by a consortium of filamentous fungi». Journal of Applied Polymer Science, 92(1), 265-271.

[119] SOWMYA, H.V., RAMALINGAPPA, M. eta KRISHNAPPA, M. 2012. «Degradation of polyethylene by Chaetomium sp. and Aspergillus flavus». International Journal of Recent Scientific Research, 3(6), 513-517.

[120] SHEIK, S., CHANDRASHEKAR, K.R., SWAROOP, K. eta SOMASHEKARAPPA, H.M. 2015. «Biodegradation of gamma irradiated low density polyethylene and polypropylene by endophytic fungi». International Biodeterioration and Biodegradation, 105, 21-29.

[121] JEYAKUMAR, D., CHIRSTEEN, J. eta DOBLE, M. 2013. «Synergistic effects of pretreatment and blending on fungi mediated biodegradation of polypropylenes». Bioresource Technology, 148, 78-85.

[122] NIMCHUA, T., PUNNAPAYAK, H. eta ZIMMERMANN, W. 2007. «Comparison of the hydrolysis of polyethylene terephthalate fibers by a hydrolase from Fusarium oxysporum LCH I and Fusarium solanif. sp. pisi». Biotechnology Journal, 2(3), 361-364.

[123] LIEBMINGER, S., EBERL, A., SOUSA, F., HEUMANN, S., FISCHERCOLBRIE, G., CAVACO-PAULO, A. et al. 2007. «Hydrolysis of PET and bis-(benzoyloxyethyl) terephthalate with a new polyesterase from Penicillium citrinum». Biocatalysis and Biotransformation, 25(2-4), 171-177.

[124] TIAN, L., KOLVENBACH, B., CORVINI, N., WANG, S., TAVANAIE, N., WANG, L. et al. 2017. «Mineralisation of ${ }^{14} \mathrm{C}$-labelled polystyrene 
plastics by Penicillium variabile after ozonation pre-treatment». New Biotechnology, 38(B), 101-105.

[125] Paço, A., Duarte, K., da Costa, J.P., Santos, P.S.M., Pereira, R., Pereira, M.E. et al. 2017. «Biodegradation of polyethylene microplastics by the marine fungus Zalerion maritimum». Science of the Total Environment, 586, $10-15$. 